\title{
Centro de estudos brasileiros em Oxford
}

\author{
RUBENS ANTONIO BARBOSA
}

Duas das prioridades do Governo brasileiro no âmbito de suas relações com o Reino Unido são a de incentivar o desenvolvimento de estudos brasileiros entre a comunidade acadêmica e fortalecer os laços institucionais entre universidades e centros de pesquisa de ambos os países.

Tendo em vista esse propósito, a Embaixada do Brasil decidiu apoiar o estabelecimento de um Centro de Estudos Brasileiros em Oxford, que contribua significativamente para o aumento do nível de informação sobre o Brasil na Europa. Os principais objetivos do Centro seriam os de organizar seminários e debates sobre os diferentes aspectos da economia e da política brasileiras, promover pesquisas e preparar, assim, o caminho para uma nova geração de acadêmicos dedicados aos estudos brasileiros.

Acordou-se que o novo Centro manteria vínculos com o St Antony's College, devido a sua tradição na área de estudos latino-americanos em geral.

\section{A Universidade de Oxford e St Antony's College}

O St Antony’s College foi fundado em 1950 já como curso de pósgraduação vinculado à Universidade de Oxford. Ainstituição é especializada em relações internacionais ededica-se ao estudo interdisciplinar de história, economia, política, sociologia e cultura dos principais países e regiões do mundo.

Na gestão de três Diretores notáveis - Sir William Deakin (1950-68), Sir Raymond Carr (1968-87) e Lord (Ralf) Dahrendorf (1987-), St Antony's tem grangeado indiscutível reputação internacional tanto em pesquisa como em ensino de pós-graduação. Em outubro de 1997, o Embaixador Marrack Goulding, que ocupava a função de Subsecretário-Geral de Assuntos Políticos da ONU, assumirá a direção do College.

O St Antony's College tem em seus quadros entre 40 e 50 Professores e Pesquisadores Associados (membros plenos), entre 200 e 250 estudantes diplomados (Assistentes) e mais de 100 "Senior Associate Members (SAMs)" - professores visitantes, políticos, diplomatas, funcionários públicos, homens de negócios, jornalistas etc. Os pontos focais para estudo e ensino no St Antony’s College são proporcionados pelos centros ligados a regiões e a países, tais quais: o Centro de Estudos Latino-Americanos, o Centro de Estudos Europeus, o 
Instituto Nissan de Estudos Japoneses, o Centro de Estudos Asiáticos (incluindo o Centro de Estudos Indianos), o Centro do Oriente Médio e o Centro da Rússia e da Europa do Leste.

\section{O Centro de Estudos Latino-Americanos}

O Centro de Estudos Latino-Americanos foi originalmente criado no St Antony's College em 1964. Em 1965 tornou-se um dos cinco centros universitários incumbidos de fomentar os Estudos Latino-Americanos nas universidades do Reino Unido.

O Centro treina estudantes de pós-graduação em disciplinas da área de Ciências Sociais e Humanidades relacionadas à América Latina; promove pesquisas e publicação de livros sobre o continente; traz a Oxford especialistas de todas as partes do mundo, incluindo da própria América Latina, e organiza extenso programa de seminários e conferências.

\section{Estudos Brasileiros}

O Centro de Estudos Latino-Americanos da Universidade de Oxford, no St Antony's College, há muito dedica-se ao ensino e à pesquisa sobre o Brasil . Alguns pesquisadores do St Antony's College, bem como de outras faculdades associadas ao Centro, interessam-se pela área de pesquisa, pesquisam e/ou supervisionam doutorandos (D Phil) que estudem o Brasil. Nos cursos de mestrado - i.e. M Phil em Estudos Latino-Americanos e M Sc. em Política Administrativa da América Latina - há cursos sobre aspectos do Brasil contemporâneo. Ao longo dos anos, vários acadêmicos brasileiros consagrados têm contribuído para o programa de seminários do Centro de Estudos LatinoAmericanos. O Centro tem ainda promovido vários programas de intercâmbio com universidades brasileiras e centros de pesquisa. Há importantes bibliotecas em Oxford, como a Bodleian, a Taylorian, a do CELA, a da Queen Elizabeth House, a do Instituto de Antropologia Social e a do Instituto de Economia, com recursos substanciais sobre o Brasil.

A indicação do Professor Leslie Bethell - Professor Emérito de História da América Latina, ex-Diretor do Instituto de Estudos Latino-Americanos da Universidade de Londres e consagrado historiador especializado nos séculos XIX e XX da história do Brasil-como Pesquisador-Chefe da Fundação Baring em estudos brasileiros junto ao St Antony’s College, em outubro de 1993, 
possibilitou ao Centro de Estudos Latino-Americanos aperfeiçoar e realçar estudos e pesquisas sobre o Brasil no campo das ciências sociais em nível de pósgraduação, reforçar o programa de seminários e conferências, estender e fortalecer o intercâmbio com instituições do Brasil, dos Estados Unidos e da Europa e atrair mais estudantes brasileiros de pós-graduação e Professores visitantes a Oxford.

\section{O Centro de Estudos Brasileiros em Oxford}

A Universidade de Oxford e a Embaixada do Brasil acordaram consolidar e promover as atividades iniciadas pelo Professor Leslie Bethell por meio da criação de um Centro de Estudos Brasileiros, estreitamente ligado, embora não integrado, ao Centro de Estudos Latino-Americanos.

Através de projetos de pesquisa, seminários, conferências e publicações, o Centro promoveria um melhor conhecimento do Brasil - sua história e cultura, sua sociedade, seu desenvolvimento econômico e político, seu lugar no mundo - no Reino Unido e na Europa em geral, nos Estados Unidos (através de uma rede que ligasse Oxford aos Centros de Estudos Brasileiros nas universidades mais importantes dos Estados Unidos), e, evidentemente, no próprio país.

Ficou decidido que a estrutura administrativa do Centro será a seguinte:

a) Diretor (pleno, com nível de Professor titular/catedrático em em tempo integral, por pelo menos cinco anos);

b) Administrador/Secretário;

c) Pesquisador Associado brasileiro em Economia;

d) Pesquisadores Visitantes; e

e) Pesquisador Associado em Cultura/Letras.

As atividades do Centro são as seguintes:

1. Coordenar e desenvolver cursos de pós-graduação e pesquisa sobre o Brasil na área de ciências sociais e humanidades, na Universidade de Oxford. Através de seu programa de palestras, seminários, debates, conferências e publicações, promover conhecimento sobre a história, a sociedade, a economia, a política e a cultura do Brasil, bem como sobre a política externa brasileira, sobretudo para o Reino Unido e a Europa de modo geral.

2. O Centro forma parte do programa de ensino e pesquisa sobre a América Latina da Universidade, e suas atividades serão supervisionadas por um Conselho de Administração, integrado por acadêmicos da Universidade de 
Oxford; a um Conselho Consultivo, cujos membros seriam selecionados dentre doadores, caberia acompanhar as atividades do Centro.

3. O Centro coordenará seu programa com o do Centro de Estudos Latino-Americanos, embora conte com Diretor e identidade acadêmica próprios.

4. O orçamento do Centro de Estudos Brasileiros será separado do orçamento do Centro de Estudos Latino-Americanos, ainda que ambos os Centros sejam administrados pela Comissão Interuniversitária da Universidade de Oxford.

5. O Diretor do Centro de Estudos Brasileiros é o responsável pelo planejamento do programa e do calendário acadêmicos.

6. O Diretor do Centro de Estudos Brasileiros preside o conselho de seleção incumbido de indicar professores e pesquisadores associados. Do conselho faz parte também um representante de St Antony’s College.

7. Os pesquisadores do Centro de Estudos Brasileiros terão acesso às facilidades do Centro de Estudos Latino-Americanos, no que se refere ao uso da biblioteca e à promoção de seminários, bem com coordenarão tais atividades com o seu Diretor, considerado membro nato da Comissão do Centro de Estudos Latino-Americanos.

8. Todos os acordos terão que ser aprovados pelo Conselho de Administração de St Antony’s College, pela Comissão Interuniversitária de Estudos Latino-Americanos da Universidade de Oxford e pelo Conselho de Decanos da Universidade.

9. Serão concedidos fundos ao Centro por um período de 5 anos, para subvenção de suas atividades (seminários, conferências, visitas de acadêmicos). Ao Diretor cabe obter recursos financeiros adicionais.

10. À Universidade de Oxford caberá fornecer instalações adequadas para o Centro - salas para o Diretor, Secretário(a), Pesquisadores, bem como permitir o uso de salas para seminários.

11. Será solicitado à Universidade (i.e. ao Conselho de Administração da Universidade, através da Comissão Interuniversitária de Estudos LatinoAmericanos) prover fundos adicionais para o(a) Secretário(a), para a aquisição de equipamentos de escritório e para custear despesas relacionadas com pesquisa e viagens, além de despesas para o funcionamento da biblioteca.

12. Como contrapartida ao financiamento do Centro de Estudos Brasileiros, o St Antony's providenciará a vinculação do Centro ao seu quadro acadêmico-institucional, o que lhe permitirá fazer uso das facilidades do College. Pesquisadores Associados e Visitantes passarão a ser membros plenos do 
St Antony's, de acordo com seus procedimentos acadêmicos de recrutamento, seleção e titulação.

13. O Centro contará com a colaboração dos acadêmicos que participarão em suas atividades, em seus programas de seminários e conferências, e, em especial, em sua administração.

14. Localização: O Centro de Estudos Brasileiros da Universidade de Oxford ficará instalado provisoriamente em 33 Beaumont Street, Oxford. Oportunamente, espera-se que possa obter um espaço adequado no Saint Antony’s College para a instalação do Centro.

15. Data de abertura: o Centro começou a funcionar em junho de 1997.

\section{O Diretor do Centro}

Ficou estabelecido que o Diretor do Centro seria um acadêmico britânico que tenha dedicado a maior parte ou parte de sua carreira ao estudo e pesquisa de temas brasileiros. Tal cargo requer qualificações acima da média e titulação acadêmica compatível com o cargo, publicação de livros, ensaios, artigos ou documentos sobre temas de interesse sobre o Brasil, assim como a participação em conferências e seminários.

Uma das principais tarefas do Diretor será a colaboração permanente com universidades, centros de pesquisa e outras instituições acadêmicas no Brasil, que poderão envidar esforços, conjuntamente com o Centro em Oxford, para promover os estudos brasileiros no Reino Unido.

O Diretor é responsável pelo Programa Anual de Atividades do Centro, assim como pela sua execução. Tal Programa deverá ser submetido e aprovado por Conselho a ser criado.

Após ter dado autorização para a criação e funcionamento do Centro, a Universidade de Oxford iniciou, em fevereiro de 1997, com publicação do anúncio correspondente, o processo de seleção para preenchimento do cargo de Diretor do Centro.

Apresentaram-se vários candidatos, e após consideração pelas instâncias competentes, a Universidade ofereceu o posto ao Professor Leslie Bethell, que o aceitou, tendo sido nomeado Diretor do Centro de Estudos Brasileiros a partir de 16 de junho de 1997.

OProfessor Leslie Bethelléo mais importantehistoriador no Reino Unido sobreaAméricaLatina, especialmente sobre o Brasil. Tendo obtido seu doutoramento em 1963, exerceu cátedras em história européia e história latino-americana nas 
Universidades de Bristol e Londres. Foi Diretor do Centro de Estudos LatinoAmericanos da Universidade de Londres entre 1986 e 1992. Além das atividades acadêmicas que desempenha em universidades e centros de pesquisa nos EUA e no Brasil, é Pesquisador-Chefe em Estudos Brasileiros no St. Antony's College desde 1993. É também assessor do Programa sobreAmérica Latina do Woodrow Center, de Washington, noquediz respeitoao Brasil.

O Professor Bethell é o organizador principal da obra Cambridge History of Latin America, de 10 volumes. É autor de The Abolition of the Brazilian Slave Trade (Cambridge, 1970) e, em colaboração com Ian Roxborough, de Latin America between the Second World War and the Cold War (Cambridge, 1992), além de numerosos ensaios, artigos e trabalhos de pesquisa sobre a história política, econômica e social do Brasil nos séculos XIX e XX, sobre a história da escravidão e do tráfico de escravos nas Américas, sobre as relações entre a Grã-Bretanha e a América Latina, no passado e no presente, sobre as relações entre os EUA e a América Latina e, mais recentemente, sobre a Guerra do Paraguai.

Recursos para manutenção do Centro de Estudos

Como resultado de trabalho junto ao setor privado brasileiro e britânico, além de Itamaraty e Ministério da Cultura, a Embaixada em Londres obteve recursos financeiros da ordem de US \$1,4 milhão para permitir a manutenção do Centro por um período de cinco anos.

Contribuíram, como doadores e fundadores do Centro: o Banco Safra, o Grupo Votorantim, as Organizações Roberto Marinho, as Culturas Inglesas de São Paulo e do Rio, a Glaxo do Brasil e a Shell do Brasil. Do lado governamental, o Ministério da Cultura e o Itamaraty.

Confirmaram contribuições igualmente as empresas britânicas Amerada Hess e Robert Fleming.

Os doadores e fundadores do Centro farão parte de um Conselho que terá por atribuição acompanhar a evolução do funcionamento do Centro, devendo para tanto reunir-se uma vez por ano.

\section{Atividades iniciais do Centro}

A Embaixada em Londres e um grupo de professores de Oxford, nomeado para interinamente decidir sobre a criação e o início das operações do 
Centro, começaram a organizar dois Seminários que terão lugar este ano em Oxford, sob a coordenação do Centro de Estudos Brasileiros: o primeiro, sobre Direitos Humanos (outubro) e o segundo sobre o tema "O Brasil no Século XXI" (dezembro).

Deverá ser incluída na programação do Presidente Fernando Henrique Cardoso, durante sua Visita de Estado em dezembro próximo, ida a Oxford para inauguração oficial do Centro de Estudos Brasileiros.

Tendo em vista a disponibilidade de recursos, que garante o funcionamento do Centro por pelo menos cinco anos, o Centro de Estudos (que nasce como um dos principais, senão o principal núcleo de estudos sobre o Brasil no exterior) poderá transfomar-se no enlace de outras instituições com interesse em estudos brasileiros na Europa e nos Estados Unidos. Para tanto, já estão sendo feitos contactos preliminares. 